\title{
Correlation of Vitamin D Status with Lipid Profile of Outpatient Department Attendees - A Cross Sectional Study in a Rural Tertiary Care Hospital of North Bengal, India
}

\author{
Ritam Banerjee ${ }^{1}$, Sandipan Datta ${ }^{2}$, Arup Jyoti Rout ${ }^{3}$ \\ 1,2 Department of Biochemistry, Maharaja Jitendra Narayan Medical College and Hospital, Cooch Behar, West Bengal, \\ India. ${ }^{3}$ Department of Community Medicine, North Bengal Medical College, Darjeeling, West Bengal, India.
}

\section{ABSTRACT}

\section{BACKGROUND}

Deficient or insufficient vitamin D status is found as a major chunk amongst all age groups all over the Indian subcontinent. Low levels of serum $25(\mathrm{OH}) \mathrm{D}$ are associated with atherogenic lipid profile, and the resultant dyslipidemia is an important risk factor for cardiovascular disease and other atherosclerotic disorders in adults. As, not much literature was available on the deficiency of vitamin D and its effects, in the North Bengal region of West Bengal, India, this study was done to find out the association between vitamin D status and lipid profile of the participants and predict the risk of dislipidaemia with changes in vitamin D status.

\section{METHODS}

430 medicine OPD attendees were selected for the study, interviewed after taking consent, blood parameters were examined and collected data were analysed for correlation and multinomial regression using SPSS v.25.

\section{RESULTS}

The mean value and standard deviation of serum $25(\mathrm{OH}) \mathrm{D}$ level was found to be $21.53 \pm 7.06 \mathrm{ng} / \mathrm{ml} .35 \%$ of vitamin D deficient subjects were found to be dyslipidemic. A negative correlation was observed between vitamin D status and total cholesterol \& LDL status. While vitamin D status changed from "Sufficient" to "Deficient", the chance of dyslipidemia increased by approximately 4.6 times.

\section{CONCLUSIONS}

Serum vitamin D influences largely the lipid profile of the study population.

\section{KEY WORDS}

Vitamin D, Serum 25 (OH) D, Dyslipidaemia, Cholesterol
Corresponding Author: Dr. Arup Jyoti Rout,

Department of Community Medicine, North Bengal Medical College, Darjeeling - 734012, West Bengal, India. E-mail: dr.arupjyoti81@gmail.com

DOI: $10.14260 /$ jemds/2021/615

How to Cite This Article:

Banerjee R, Datta S, Rout AJ. Correlation of vitamin $D$ status with lipid profile of outpatient department attendees: a cross sectional study in a rural tertiary care hospital of North Bengal, India. J Evolution Med Dent Sci 2021;10(35):3012-3016, DOI: 10.14260/jemds/2021/615

Submission 11-01-2021, Peer Review 21-07-2021, Acceptance 27-07-2021, Published 30-08-2021.

Copyright (c) 2021 Ritam Banerjee et al. This is an open access article distributed under Creative Commons Attribution License [Attribution 4.0 International (CC BY 4.0)] 


\section{BACKGROUND}

Vitamin D is essential for life in all higher organisms and is found as cholecalciferol (Vitamin D3) in vertebrates. ${ }^{1}$ In humans, most of the vitamin D is synthesized cutaneously through sun-light exposure (by ultraviolet B radiation) while the remaining vitamin $\mathrm{D}$ is obtained from the diet.2,3,4 The total vitamin $\mathrm{D}$ is immediately hydroxylated by the liver to form 25-hydroxyvitamin D [25(OH)D] which is the predominant form of the circulating vitamin D. ${ }^{5}$ In this article Vitamin D and $25(\mathrm{OH}) \mathrm{D}$ have been used interchangeably.

The binding of vitamin D with high-affinity vitamin D receptor (VDR) which acts as a ligand-activated transcription factor, is responsible for its metabolic activities. ${ }^{6}$ Vitamin D reduces the production of IL-2, interferons and stimulates the T-helper type 2 lymphocytes, resulting in a reduction of matrix metalloproteinases and restricting atherosclerotic plaque progression. ${ }^{7}$ It also plays an important role in endothelial function, blood pressure control, calcification of the coronary vasculature, increased vascular resistance and prevention of CVD. 8

Recent reports have found that hypo $25(\mathrm{OH}) \mathrm{D}$ is associated with atherosclerosis, hypertension, myocardial infarction and stroke.9,10,11,12 Observational studies have demonstrated that while sufficient serum $25(\mathrm{OH}) \mathrm{D}$ is associated with a favourable lipid profile, low levels of it, is associated with an atherogenic lipid profile and the resultant dyslipidaemia is an important risk factor for atherosclerosis and cardiovascular disease in adulthood.13,14

Vitamin D deficiency or insufficiency prevails all over the Indian subcontinent, among all age groups.5,15,16 As per available literature, not too many articles have been found on the deficiency of vitamin D and its effects, especially for the North Bengal region of West Bengal, India. To enlighten on different aspects of vitamin D deficiency, a larger study was undertaken at North Bengal Medical College and Hospital. An article from the data so collected has already been published with the title "Correlation of vitamin D status with glycaemic status of individuals: a cross-sectional study in a rural tertiary care hospital of North Bengal, India".17 The present study was done, as a part of the larger study, with the following objectives.

\section{Objectives}

1. To find out the association between vitamin D status and lipid profile of study participants

2. To find out the correlation between vitamin D level and different serum lipids

3. To predict the risk of dyslipidaemia with the change of vitamin D status.

\section{METHODS}

Post ethical clearance of Institutional Ethics Committee, a cross-sectional study was planned and undertaken for 1 year from July 2016 to June 2017 among the medicine OPD patients with a sample size of 430.17
In medicine OPD, every alternate attendee, of either sex, were approached for being a study subject. Attendees having frank diabetes, autoimmune diseases, chronic kidney \& liver disorders, morbidly obese, immunocompromised, on hormone replacement therapy, taking serum lipid profile, blood glucose and serum $25(\mathrm{OH})$ D level altering drugs, or substance abusers, were excluded from the study. Using the same collected data of the larger study, though, on different blood parameters, the present study analysis was made.

\section{Data Collection Procedure}

Written informed consents were obtained from the eligible \& willing subjects followed by their interview, using a prestructured, pretested questionnaire. Body mass index (BMI) was calculated using the formula [Weight in $\mathrm{Kg} / \mathrm{Height}$ in $\mathrm{mt}^{2}$ ]. For lab investigations, blood samples were collected from the antecubital vein after 8 hours of overnight fasting, in fluoride \& clotted vials. Within 30 - 45 minutes of collection of samples, serum was separated by centrifuge machine.

\section{Estimation of Blood Parameters}

An automated analyzer (Erba Mannheim XL-600 \& EM-360) was used for the estimation of blood parameters. Serum calcium was estimated using OCPC (O-Cresolphthalein Complex one) method. Cholesterol oxidase-peroxidase (CHOD / PAP) method for total cholesterol and GPO (glycerol phosphate oxidase) method for triglycerides were used. Estimation of HDL was done by modified polyvinyl sulfonic acid (PVS) and polyethylene glycol methyl ether (PEGME) coupled classic precipitation method with the improvement in using optimized quantities of PVS/PEGME and selected detergents. Estimation of VLDL \& LDL was done using the Friedewald formula. ${ }^{18}$ Serum $25(\mathrm{OH})$ D levels were estimated by the ELISA method.

\section{Statistical Analysis}

Collected data were checked for completeness \& consistency and entered in Microsoft Excel version 2007 and were cleaned. Codification of data and Pearson's correlation, multinomial logistic regression analysis was done in SPSS version 22. Results are presented through tables in the form of percentages and proportions. P-value $<0.05$ was considered statistically significant.

\section{Operational Definitions}

Dyslipidaemia Was Defined (ATP III) as One or More of the Following:19

- Hypercholesterolemia: Total cholesterol more than 200 $\mathrm{mg} / \mathrm{dL}$

- Hypertriglyceridemia: Triglycerides more than $150 \mathrm{mg} /$ $\mathrm{dL}$

- High LDL-C: low density lipoprotein-cholesterol (LDL-C) more than $130 \mathrm{mg} / \mathrm{dL}$

- High VLDL-C: very low density lipoprotein-cholesterol (VLDL-C) more than $30 \mathrm{mg} / \mathrm{DL}$

- Low HDL-C: high-density lipoprotein-cholesterol (HDL-C) levels $<40 \mathrm{mg} / \mathrm{dL}$ for men and $<50 \mathrm{mg} / \mathrm{dL}$ for women 
Vitamin D Status 20,21

\begin{tabular}{|cc|}
\hline Status of Vitamin D & Level of Serum [25(0H)D] in $\mathbf{~ n g / m l ~}$ \\
Deficient & $<20$ \\
Insufficient & $20-29$ \\
Sufficient & $30-70$ \\
Potential Toxicity & $>\quad 70$ \\
\hline
\end{tabular}

\section{RESULTS}

\begin{tabular}{|ccc|}
\hline Blood Parameters & Mean & Std. Deviation \\
Vitamin D Level & 21.5322 & 7.05670 \\
Cholesterol & 170.50 & 33.345 \\
Triglyceride & 146.45 & 66.123 \\
HDL & 51.13 & 6.826 \\
VLDL & 28.53 & 13.062 \\
LDL & 90.56 & 27.957 \\
Calcium & 8.7224 & 0.78312 \\
\hline Table 1. Different Blood Parameters of the Study Population $(\boldsymbol{N}=\mathbf{4 3 0})$ \\
\hline
\end{tabular}

\begin{tabular}{|c|c|c|c|c|c|}
\hline $\begin{array}{l}\text { Vitamin D } \\
\text { Status }\end{array}$ & $\underset{\mathbf{a}}{\text { Dyslipidaemi }}$ & $\begin{array}{l}\text { Lipid Status } \\
\text { Normal Lipid } \\
\text { Profile }\end{array}$ & Total & $\begin{array}{l}\text { Chi } \\
\text { Square }\end{array}$ & $\begin{array}{c}\mathbf{P} \\
\text { Value }\end{array}$ \\
\hline Deficient & $70(35)$ & $130(65)$ & $200(100)$ & \multirow{4}{*}{$\begin{array}{l}13.73 \\
\mathrm{df}=2\end{array}$} & \multirow{4}{*}{$<0.05$} \\
\hline Insufficient & $45(25)$ & $135(75)$ & $180(100)$ & & \\
\hline Sufficient & $5(10)$ & $45(90)$ & $50(100)$ & & \\
\hline Total & $120(7.90)$ & $310(2.10)$ & $430(100)$ & & \\
\hline \multicolumn{6}{|c|}{$\begin{array}{c}\text { Table 2. Distribution of Study Population According to Their Vitamin D } \\
\text { Status and Lipid Profile }\end{array}$} \\
\hline
\end{tabular}

\begin{tabular}{|ccc|}
\hline Blood Parameters & Pearson's Correlation & Significance Level \\
Cholesterol & -0.35 & $<0.05$ \\
Triglyceride & -0.203 & $<0.05$ \\
HDL & 0.026 & 0.585 \\
VLDL & -0.16 & $<0.05$ \\
LDL & -0.358 & $<0.05$ \\
Calcium & 0.53 & $<0.05$ \\
\hline Table 3. Correlation between Serum 25(OH)D with Different Blood \\
\\
Parameters \\
\hline
\end{tabular}

\begin{tabular}{|c|c|c|c|c|c|}
\hline \multicolumn{6}{|c|}{ Multinomial Regression Analysis } \\
\hline \multirow{2}{*}{ Lipid State ${ }^{a}$} & \multirow[t]{2}{*}{$\begin{array}{l}\text { Predictor } \\
\text { Variables }\end{array}$} & \multirow[t]{2}{*}{$\begin{array}{l}\text { Adjusted } \\
\text { Odds Ratio } \\
\text { (AOR) }\end{array}$} & \multicolumn{2}{|c|}{$\begin{array}{l}95 \% \text { Confidence } \\
\text { Interval for AOR }\end{array}$} & \multirow{2}{*}{ Sig. } \\
\hline & & & $\begin{array}{l}\text { Lower } \\
\text { Bound }\end{array}$ & $\begin{array}{l}\text { Upper } \\
\text { Bound }\end{array}$ & \\
\hline \multirow{6}{*}{ Dyslipidaemia } & Age & 1.011 & 0.992 & 1.030 & 0.262 \\
\hline & Female & 1.512 & 0.977 & 2.340 & 0.063 \\
\hline & Male & 0 & & & \\
\hline & Vitamin D Deficient & 4.597 & 1.637 & 12.911 & 0.004 \\
\hline & Vitamin D Insufficient & 3.176 & 1.173 & 8.597 & 0.023 \\
\hline & Vitamin D Sufficient & 0 & & & \\
\hline \multicolumn{6}{|c|}{$\begin{array}{c}\text { Table 4. Multinomial Logistic Regression Showing Risk of } \\
\text { Dyslipidaemia }\end{array}$} \\
\hline
\end{tabular}

It was found that the Mean \pm SD of the age of study participants was $37.47 \pm 12.63$ years. Most of the participants were males $(54.7 \%)$. Sufficient vitamin D status was the lowest found (11.63\%) while Deficient status was the most $(46.51 \%)$ among the subjects. $41.86 \%$ of participants were found to be with insufficient vitamin D status. ${ }^{17}$ Mean \pm SD of serum $25(\mathrm{OH})$ D level was found to be $21.53 \pm 7.06 \mathrm{ng} / \mathrm{ml}$ while that of cholesterol and triglycerides were $170.50 \pm 33.35$ $\mathrm{mg} / \mathrm{dl}$ and $146.45 \pm 66.12 \mathrm{mg} / \mathrm{dl}$ respectively (table 1 ). Among the total 200 vitamin D deficient study subjects, 70 (35\%) were found to be a dyslipidemic while, $45(90 \%)$ of the total 50 study subjects with sufficient vitamin D status were found to be with normal lipid profile. The difference in lipid profile among different vitamin D status was statistically significant (Table 2). Statistically significant, medium negative correlation was observed between vitamin D status and total cholesterol (-0.35) \& LDL status (-0.358). Though a weak positive correlation was found between vitamin D and HDL it was not statistically significant (Table 3 ). Taking 'normal lipid profile' as the reference category for the dependent variable and adjusting other independent variables, in multinomial regression analysis showed that, with change in vitamin D status from "Sufficient" to "Insufficient" and "Deficient", risk of dyslipidaemia increased by approximately 3.2 times and 4.6 times respectively and both of the findings were statistically significant (Table 4).

\section{DISCUSSION}

\section{Vitamin D Deficiency}

In Asian sun-rich countries, vitamin D deficiency is multifactorial. Phosphate and phytate prevalent high fibre diet leads to reduced absorption of vitamin D after oral intake. The increased melanin of the dark complexion population may reduce vitamin $D$ production by absorbing UVB rays. ${ }^{22}$ Moreover, increased indoor occupational activities, increased pollution, and genetic predisposition contributes to vitamin $\mathrm{D}$ deficiency. ${ }^{23}$ In the present study, vitamin D deficient subjects were $46.51 \%$ while $41.86 \%$ were vitamin D insufficient. A study on Asian subjects done by Soo Lim et al. showed that $51.6 \%$ had vitamin D insufficiency. ${ }^{24}$ Another study in the North Indian community had shown a much higher i.e. $75.8 \%$ of participants were vitamin D deficient. ${ }^{19}$ Ethnic differences, varying degrees of exposure to sunlight might have played a role behind such diverse findings.

\section{Vitamin D Deficiency Affecting Lipid Profile}

Vitamin D has been suggested to affect the regulation of lipid metabolism directly, due to its involvement in the synthesis of bile acid in the liver. ${ }^{25}$ Chaudhuri et al. had reported that 25(OH)D deficiency was independently associated with dyslipidaemia in Indian subjects. ${ }^{26}$

The present study results showed an inverse correlation of serum vitamin D3 with serum cholesterol, triglyceride, LDL and VLDL while, a positive correlation of serum $25(\mathrm{OH}) \mathrm{D}$ and serum HDL. Also, the risk of dyslipidaemia increases with low vitamin D levels. The results are in conjunction with some of the recent association with studies done on the Indian population, where vitamin D concentration was inversely correlated with atherogenic lipids (TC, TG, and LDL) and showed a strong positive correlation with athero-protective lipids (HDL).5,25,27,28,29,30 Even studies from abroad, like Gaddipati et al. a study done on Americans and Jungert A et al. study in Germany, also showed that serum vitamin D levels were negatively correlated with total cholesterol, triglycerides and LDL and positively correlated with HDL. ${ }^{31,32}$ In contrast, Chiu showed no relationship between serum levels of 25 $(\mathrm{OH}) \mathrm{D}$ and TG or HDL cholesterol in healthy subjects. ${ }^{33}$ Similarly, a study done by Garry John and colleagues among 170 UK Bangladeshi healthy adults showed no relationship between $25(\mathrm{OH}) \mathrm{D}$ and TG or HDL cholesterol. ${ }^{34}$

The coexistence of hypovitaminosis D and hypercholesterolemia may be explained via photo metabolism. Sunlight converts squalene, in exposed skin, into 7-dehydrocholesterol, vitamin D and photo metabolites of 
vitamin D. ${ }^{35}$ The 7-dehydrocholesterol pathway in the liver is common for cholesterol and $25(\mathrm{OH}) \mathrm{D}$ synthesis. ${ }^{36}$ In the absence of effective sunlight, its metabolic pathway is diverted into the formation of cholesterol. ${ }^{34}$ LDL cholesterol has been postulated as a precursor of previtamin D. So, a defect in LDL receptors will increase serum cholesterol due to lower cholesterol uptake with a resultant decrease in serum 25 $(\mathrm{OH}) \mathrm{D}$ as both share the common synthetic pathway. ${ }^{37}$

Vitamin D may regulate triglyceride metabolism by causing the expression of VLDL cholesterol receptors in some types of cells. 38 Apart from this, few more important mechanisms have been postulated. Vitamin D enhances intestinal calcium absorption. This increased serum calcium could then reduce serum triglycerides by reducing its hepatic formation and secretion. ${ }^{39}$ Vitamin D has a suppressive effect also on serum PTH concentration. As plasma post heparin lipolytic activity is reduced by elevated PTH concentration, low serum PTH may reduce serum triglycerides via increased peripheral removal. ${ }^{40,41}$ Again, when vitamin $D$ is deficient, the risk of insulin resistance increases and this is associated with defective lipoprotein metabolism resulting in an elevation of VLDL cholesterol and triglycerides and a decrease in HDLC. $38,42,43$ Even, Garry John study depicting no relationship between $25(\mathrm{OH}) \mathrm{D}$ and TG or HDL cholesterol, admitted that the serum level of $25(\mathrm{OH}) \mathrm{D}$ is an independent predictor of fasting apolipoprotein $\mathrm{A}_{1}{ }^{33}$ This apolipoprotein $\mathrm{A} 1$ is an essential part of HDL cholesterol that acts as a scavenger of cholesterol from tissues and transports it to the liver. ${ }^{44}$

\section{CONCLUSIONS}

It can be concluded that serum vitamin $\mathrm{D}$ influences largely the lipid profile of individuals. As serum vitamin D shows an inverse correlation with atherogenic lipids, dyslipidemic cardiovascular risks may be an indirect result of vitamin $D$ deficiency. However, to establish a causal relationship between vitamin $\mathrm{D}$ status and lipid status of individuals, multicentric, large scale, longitudinal studies are recommended.

\section{Limitations}

As the present study is cross-sectional, the causality effect can't be determined. Variation in the polymorphisms of vitamin $\mathrm{D}$ binding protein (DBP) and vitamin $\mathrm{D}$ receptor (VDR), sunlight exposure, and the effect of vitamin D supplementation on weight gain also needs to be considered.

Data sharing statement provided by the authors is available with the full text of this article at jemds.com.

Financial or other competing interests: None.

Disclosure forms provided by the authors are available with the full text of this article at jemds.com.

\section{REFERENCES}

[1] Peterson CA, Tosh AK, Belanchia AM. Vitamin D insufficiency and insulin resistance in obese adolescents. Ther Adv Endocrinol Metab 2014;5(6):166-89.
[2] Al-Mogbel ES. Vitamin D status among adult Saudi femalesvisiting Primary Health Care Clinics. Int J Health Sci (Qassim) 2012;6(2):116-26.

[3] Cipriani C, Pepe J, Piemonte S, et al. Vitamin D and its relationship with obesity and muscle. Int J Endocrinol 2014;2014:841248.

[4] Jorde R, Grimnes G. Vitamin D and metabolic health with special reference to the effect of vitamin D on serum lipids. Prog Lipid Res 2011;50(4):303-12.

[5] Patel PA, Patel PP, Mughal Z, et al. Inter-relationship between serum 25-hydroxyvitamin D concentration and lipid profiles in premenopausal Indian women. Indian J Endocr Metab 2017;21(1):96-101.

[6] Cantorna MT, Zhu Y, Froicu M, et al. Vitamin D status, 1, 25-dihydroxyvitamin D3, and the immune system. The American Journal of Clinical Nutrition 2004;80(Suppl 6):1717S-20S

[7] Andress DL. Vitamin D in chronic kidney disease: a systemic role for selective vitamin D receptor activation. Kidney International 2006;69(1):33-43.

[8] Nemerovski CW, Dorsch MP, Simpson RU, et al. Vitamin D and cardiovascular disease. Pharmacotherapy 2009;29(6):691-708.

[9] De Boer IH, Kestenbaum B, Shoben AB, et al. 25hydroxyvitamin $D$ levels inversely associate with risk for developing coronary artery calcification. Journal of the American Society of Nephrology 2009;20(8):1805-12.

[10] Forman JP, Giovannucci E, Holmes MD, et al. Plasma 25hydroxyvitamin $D$ levels and risk of incident hypertension. Hypertension 2007;49(5):1063-9.

[11] Scragg R, Jackson R, Holdaway IM, et al. Myocardial infarction is inversely associated with plasma 25hydroxyvitamin D3 levels: a community-based study. International Journal of Epidemiology 1990;19(3):55963.

[12] Poole KE, Loveridge N, Barker PJ, et al. Reduced vitamin D in acute stroke. Stroke 2006;37(1):243-5.

[13] Polkowska A, Głowińska B, Tobiaszewska M, et al. Risk factors for cardiovascular disease in children with type 1 diabetes in 2000-2010 in Podlasie Province. Pediatric Endocrinology Diabetes and Metabolism 2015;20(2):4754.

[14] Wang H, Xia N, Yang Y, et al. Influence of Vitamin D supplementation on plasma lipid profile. A meta-analysis of randomised control trials. Lipids Health Disease 2012;11:42.

[15] Goswami R, Mishra SK, Kochupillai N. Prevalence \& potential significance of vitamin D deficiency in Asian Indians. Indian Journal of Medical Research 2008;127(3):229-38.

[16] Pittas AG, Dawson-Hughes B. Vitamin D3 and Diabetes. J Steroid Biochem Mol Biol 2010;121(1-2):425-9.

[17] Konar S, Banerjee R. Correlation of vitamin D status with glycemic status of individuals- a cross sectional study in a rural tertiary care hospital of North Bengal, India. J Evolution of Med Dent Sci 2020;9(5):252-5.

[18] Friedewald WT, Levy RI, Fredrickson DS. Estimation of the concentration of low-density lipoprotein cholesterol in plasma, without use of the preparative ultracentrifuge. Clin Chem 1972;18(6):499-502.

[19] Expert Panel on Detection, Evaluation and Treatment of High Blood Cholesterol in Adults. Executive summary of the third report of the National Cholesterol Education 
Program (NCEP) Adult Treatment Panel (ATP III). JAMA 2001;285(19):2486-97.

[20] Holick MF. Vitamin D deficiency. N Engl J Med 2007;357(3):266-81.

[21] Braun TR, Been LF, Blackett PR, et al. Vitamin D deficiency and cardio-metabolic risk in a north Indian community with highly prevalent type 2 diabetes. J Diabetes Metab 2012;3:10 4172/2155-6156.1000213.

[22] Holick MF. Vitamin D: a millenium perspective. Journal of Cellular Biochemistry 2003;88(2):296-307.

[23] Londhey V. Vitamin D deficiency: Indian scenario. Journal Association Physicians India 2011;59:695-6.

[24] Lim S, Kim MJ, Choi SH, et al. Association of Vitamin D deficiency with incidence of type 2 diabetes in high-risk Asian subjects. The American Journal of Clinical Nutrition 2013;97(3):524-30.

[25] Jiang W, Miyamoto $\mathrm{T}$, Kakizawa $\mathrm{T}$, et al. Inhibition of LXRalpha signaling by Vitamin D receptor: possible role of VDR in bile acid synthesis. Biochemical and Biophysical Research Communications 2006;351(1):176-84.

[26] Chaudhuri JR, Mridula KR, Anamika A, et al. Deficiency of 25-hydroxyvitamin $\mathrm{D}$ and dyslipidemia in Indian subjects. Journal of Lipids 2013;2013:623420.

[27] Kumari K, Kumar R, Sharan S. Assessment of Vitamin D and its correlation with lipid markers among adult female during the course of pregnancy in and around Dhanbad, Jharkhand. International Journal of Contemporary Medical Research 2018;5(6):F8-F10.

[28] Manohari AL, Samhitha A, Girijavani DSS, et al. A study of association of vitamin $D$ with serum lipids in patients with type 2 diabetes. Indian Journal of Applied Research 2018;8(3):51-3.

[29] Mahajan P, Bhatia AS. Diminished levels of Vitamin D and altered lipid profile. Journal of Medical Science and Clinical Research 2017;5(6):23694-7.

[30] Giri R, Rai R, Verma RK, et al. Correlation between Vitamin $\mathrm{D}$ and lipid profile in patients with ischemic stroke. Int J Res Med Sci 2016;4(6):2309-12.

[31] Gaddipati VC, Bailey BA, Kuriacose R, et al. The relationship of vitamin $\mathrm{D}$ status to cardiovascular risk factors and amputation risk in veterans with peripheral arterial disease. Journal of the American Medical Doctors Association 2011;12(1):58-61.
[32] Jungert A, Roth HJ, Neuhauser-Berthold M. Associations of serum 25 hydroxycholecalciferol and parathyroid hormone with serum lipids differ by sex and vitamin D status. Public Health Nutrition 2015;18(9):1684-91.

[33] Chiu KC, Chu A, Go VLW, et al. Hypovitaminosis D is associated with insulin resistance and $\beta$ cell dysfunction. Am J Clin Nutr 2004;79(5):820-5.

[34] John WG, Noonan K, Mannan N, et al. Hypovitaminosis D is associated with reductions in serum apolipoprotein A1 but not with fasting lipids in British Bangladeshis. Am J Clinl Nutr 2005;82(3):517-22.

[35] Grimes DS, Hindle E, Dyer T. Sunlight, cholesterol and coronary heart disease. QJM: An International Journal of Medicine 1996;89(8):579-90.

[36] Lips P. Vitamin D physiology. Progress in Biophysics and Molecular Biology 2006;92(1):4-8.

[37] Al-Dhubaibi MS. Association between Vitamin D deficiency and psoriasis: an exploratory study. Int J Health Sci (Qassim) 2018;12(1):33-9.

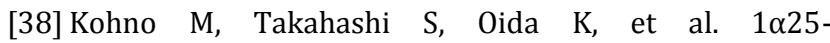
dihydroxyvitamin D3 induces very low density lipoprotein receptor mRNA expression in HL-60 cells in association with monocytic differentiation. Atherosclerosis 1997;133(1):45-9.

[39] Choi HS, Kim KA, Lim CY, et al. Low serum vitamin D is associated with high risk of diabetes in Korean adults. Journal of Nutrition 2011;141(8):1524-8.

[40] Lacour B, Basile C, Drüeke T, et al. Parathyroid function and lipid metabolism in the rat. Mineral and Electrolyte Metabolism 1982;7(3):157-65.

[41] Song SJ, Si S, Liu J, et al. Vitamin D status in Chinese pregnant women and their newborns in Beijing and their relationships to birth size. Public Health Nutrition 2013;16(4):687-92.

[42] Ginsberg HN, Zhang YL, Hernandez AO. Regulation of plasma triglycerides in insulin resistance and diabetes. Archives of Medical Research 2005;36(3):232-40.

[43] Karnchanasorn R, Ou HY, Chiu KC. Plasma 25hydroxyvitamin D levels are favorably associated with beta-cell function. Pancreas 2012;41(6):863-8.

[44] Saedisomeolia A, Taheri E, Djalali M, et al. Association between serum level of vitamin $D$ and lipid profiles in type 2 diabetic patients in Iran. Journal of Diabetes \& Metabolic Disorders 2014;13(1):7. 